\title{
Stress Levels, Attitudes towards Specialty and Job Satisfaction among Indian Urologists- A Cross Sectional Study
}

\author{
Mahantesh Todakar ${ }^{1}$, Gajanan Bhat ${ }^{2}$, Vikram Prabha ${ }^{3}$, Shishir Devaraju4, Prakash H. S. ${ }^{5}$ \\ ${ }^{1}$ Assistant Professor, Department of Urology and General Surgery, Belgaum Institute of Medical Sciences, Belagavi, \\ Karnataka, India. ${ }^{2}$ Consultant Urologist, Department of Urology, International Diploma in Reproductive Health \\ Management/Karnataka State Health Department of India, Karnataka, India. ${ }^{3}$ Associate Professor, Department of \\ Urology, JN Medical College, Kaher, Belagavi, Karnataka, India. ${ }^{4}$ Assistant Professor, Department of Urology, JN \\ Medical College, Kaher, Belagavi, Karnataka, India. ${ }^{5}$ Associate Professor, Department of Urology, \\ Mysore Medical College, Mysore, Karnataka, India.
}

\section{ABSTRACT}

\section{BACKGROUND}

Urology is a vast specialty in medical science and a career as a urologist is demanding, both physically and mentally. The attitudes towards specialty, stress levels, causes of stress, and job satisfaction were assessed among Indian Urologists.

\section{METHODS}

Three hundred pretested questionnaires were provided to the Urologists attending various national level conferences in India out of which 208 were received back. The collected data were statistically analysed using SPSS Version 20.

\section{RESULTS}

Around 39\% of urologists expressed that they are not happy, being a urologist. Given a chance, $52.9 \%$ of urologists denied taking Medicine again as their career choice at this point of time and wished to change their profession from medicine to different fields. Around $42 \%$ of urologists feel stressed at workplace and stress is more among young urologists and urologists involved in private practice.

\section{CONCLUSIONS}

There is high prevalence of stress among Indian urologists especially young and free-lancing urologists. MCI and USI need to look into these matters and initiate problem preventing and problem solving strategies as there is a large amount of evidence regarding the ill effects of high stress levels and burnout.

\section{KEY WORDS}

Urology, Stress, Burnout, Job Satisfaction
Corresponding Author:

Dr. Prakash H. S.,

Associate Professor,

Department of Urology,

Mysore Medical College \& Research Institutue, Mysore,

Karnataka, India.

E-mail: drhsprakash@gmail.com

DOI: $10.14260 /$ jemds/2019/679

Financial or Other Competing Interests: None.

How to Cite This Article:

Todakar M, Bhat G, Prabha V, et al. Stress levels, attitudes towards specialty and job satisfaction among Indian urologists- a cross sectional study. J. Evolution Med. Dent. Sci. 2019;8(42):3130-3134, DOI: 10.14260/jemds/2019/679

Submission 27-08-2019, Peer Review 06-10-2019, Acceptance 12-10-2019, Published 21-10-2019. 


\section{BACKGROUND}

India has more than eight lakh allopathic doctors who play an important role in the management of health care system. But their own mental health condition is alarming which Indian Medical Association calls it as Public health crisis. Reasons for the stress and burn out vary among various medical specialties. Surgeons are prone for high stress levels, burnout and psychiatric morbidity. ${ }^{1}$ Personal and familial factors are protective but professional factors play significant role in these phenomena. ${ }^{1}$

Urologists often find themselves in stressful environments that are detrimental to their personal health and their social wellbeing and more often than not, this affects their professional judgement. There is a huge gap in the knowledge pertaining to the understanding of these stress levels and their subsequent effect on the performance of the doctor and this chasm is particularly glaring in Indian Urologists. This study aims to bridge this gap and provide a better understanding and open newer avenues toward accessing help with respect to stress related problems and evaluate job satisfaction in one of the highly lucrative and yet immensely stressful medical field. Several studies have been done to assess the stressors and Job satisfaction among Urologists among developed countries, but studies related to stress among Indian urologists are very limited which prompted us to design this study to evaluate stress and Job satisfaction among Indian Urologists.

\section{METHODS}

The study design included a questionnaire which was required to be answered anonymously. It was a cross sectional survey and included various national level conferences across different regions of India which saw a confluence of urologists with varied levels of experience and seniority and hailing from different parts of the country. It was a yearlong study conducted between January 2018 and January 2019. The institutional ethical committee clearance was obtained. Data was collected through the questionnaires. It was pretested at a state level conference. Necessary permits were obtained from the organizing authorities of the event. An informed verbal consent was obtained from urologists. The urologists were selected on the basis of their availability and questionnaires were handed out by the study team. They were asked to return the completed questionnaires to members of the study team. The questionnaire covered demographic characteristics, seven multiple choice and seven open-ended questions. Possible influences were selected on the basis of literature reviews and discussions with senior urologists.

The initial part of questionnaire was related to attitudes towards specialty, reasons for selecting urology as a career choice, views regarding the urology subject and super specialty, and reasons for considering change of specialty. Second part of the questionnaire enquired about stress factors, job satisfaction and effect of various government schemes on their clinical practice in Urology. Last two questions were open-ended where the urologists had an opportunity to write comments about their opinion regarding the good and the bad aspects in urology. Data were double entered by two operators and was statistically analyzed using IBM SPSS version 20 statistics software. Percentages were computed for categorical outcomes, mean and standard deviation for numerical outcomes.

\section{RESULTS}

Three hundred pretested questionnaires were provided to the Urologists attending various national level conferences in India out of which 208 were received back. Response rate was $69 \%$. Minimum age noted was 26 years and maximum aged person was 63 years old with the mean age of 39+/_ 12 years. Around $22 \%$ of the urologists belonged to suburban areas, $56 \%$ belonged to urban and $22 \%$ were from metro cities. The Area of practice is displayed in Table 1. Maximum work experience in Urology noted was 25 years and minimum was 1 year. Around $16 \%$ of urologists have done fellowships in various fields majority being in Paediatric urology. Other fellowships mentioned were Laparoscopy, Endourology, minimal access and Rnal Transplant and dialysis access fellowships.

Around $55.5 \%$ of urologists express that they are happy being urologist. 39\% say they are not happy and around 6\% say they are somewhat happy. Given a chance $52.9 \%$ of urologists denied taking Medicine as their courier again, at this point of time. And they would shift to other fields of their interest like business (23\%), lawyer (3.8\%), engineering $(3.2 \%)$, politics (2\%), music and art, consultancy/job advisor, administrative service, army, farmer, photography etc. Four percent of urologists mentioned that they would do anything else other than Medical work and did not mention what exactly they want to do. Around $8 \%$ of urologists want to be doctors only but would love to switch to other specialties of Medicine.

$42 \%$ of urologists are stressed at workplace whereas $58 \%$ of urologists don't feel stressed at workplace. Various causes for stress are mentioned in Table 2. Around $45.8 \%$ of people expressed that they are affected by the various government laws and schemes like National Medical Commission bill (NMC), Ayushman Bharat schemes, consumer protection act, KPME act in Karnataka, fear of litigation and fear of violence by public etc. Out of 208 urologists, 112 of them (54.2\%) expressed, they are not affected by the government acts. Question on how government laws are affecting urologists; revealed many interesting facts (Table 3). Question on job satisfaction revealed around $40 \%$ of urologists are very satisfied. $48 \%$ are somewhat satisfied $10 \%$ are ambivalent and $2 \%$ of them express they are somewhat dissatisfied. Our study revealed, average monthly income of Indian urologists 0-2 lakhs - 45.2\%; 2-5 lakhs- 35.7\%; 5-10 lakhs- 14.3\%; 4.8\% - >10 lakhs. Comments on what is one best thing and one bad thing about Urology are mentioned in Table 4 and 5.

\begin{tabular}{|c|c|c|}
\hline & Frequency & Valid Percent \\
\hline Teaching institute & 68 & $33.3 \%$ \\
\hline Private Practice & 80 & $39.2 \%$ \\
\hline Both & 56 & $27.5 \%$ \\
\hline \multicolumn{3}{|c|}{ Table 1. Area of Practice } \\
\hline
\end{tabular}




\begin{tabular}{|c|}
\hline High workload, Operative stress, Challenges to perform better/ decision making \\
\hline Too many stringent government laws and schemes and interference in the work \\
\hline Fear of violence from public \\
\hline Dealing with Management, Administrative work \\
Limited Resources, Poor support staff \\
\hline Urology is getting saturated, Peer competition, Difficult colleagues or staff \\
\hline Lower remuneration, Bargaining by patients on costs \\
\hline Table 2. Causes of Stress in Urology; Some Common Comments \\
\hline
\end{tabular}

\begin{tabular}{|c|}
\hline I feel helpless; I feel my hands are tied \\
\hline Less incentives work double \\
\hline Politicians are dictating terms for Medicos \\
No freedom to practice and flourish \\
\hline $\begin{array}{c}\text { There is high difference between the Indian medical charges and medical charges } \\
\text { abroad; One of the reasons for the doctors leaving the country }\end{array}$ \\
\hline $\begin{array}{c}\text { Stringent laws and rate fixing by government should not be tolerated by doctors in } \\
\text { India }\end{array}$ \\
\hline $\begin{array}{c}\text { Politicians should not control medical professionals; medical professionals should by } \\
\text { themselves have a morality }\end{array}$ \\
\hline $\begin{array}{c}\text { Feeling low in confidence in every attending patient. Don't want to take up scheme or } \\
\text { low yield patients }\end{array}$ \\
\hline Becoming more n more conservative n less risk-taking behaviour \\
\hline Table 3. Effect of New Government Schemes and Acts like NMC Bill, \\
Ayushman Bharat Schemes, Consumer Protection Act etc.
\end{tabular}

\begin{tabular}{|c|}
\hline Nothing \\
\hline Can practice anywhere \\
\hline Least emergencies, Voluminous elective surgery, Less postop care \\
\hline $\begin{array}{c}\text { JOB satisfaction due to patient satisfaction, Patient compliance, Rewarding, Cures, } \\
\text { less mortality, good and fast and Complete pain relief after stone removal }\end{array}$ \\
\hline Interesting subject, Easy to learn and good income, Ever growing, advancement \\
\hline Minimally invasive, Endourology challenges, Stress relieving, Variety \\
\hline Minimally invasive, good outcome, independency, minimal emergency \\
\hline Many \\
\hline Table 4. What is One Best Thing about Urology- \\
Some of the Common Comments \\
\hline
\end{tabular}

\section{Nothing}

Occupational hazards- Operating surgeon's position, Radiation exposure

Getting Saturated, trained general surgeons encroaching on our procedures Surgery fees going down with increasing competition Cost of instruments: Fibreoptic scopes and Laser are costly Reoccurrence

Not on par with CTVS/Neuro

Lack of teaching institutes and good teaching

My son feels shy in telling others that my father is a urine surgeon

Society is still not well aware of the branch as a specialty

Table 5. What is one Bad Thing about UrologySome of the Common Comments

\section{DISCUSSION}

The present study is the first to analyse stress levels, job satisfaction and attitudes towards specialty among Indian urologists. For decades urologists are considered as very happy, charming and satisfied personalities. But in the last decade many research works revealed high levels of burnout among Urologists. Even in our study, given a chance, $52.9 \%$ of urologists denied to take Medicine again as their courier at this point of time and they would do anything else other than medical work. Today patients and public have high expectations. And this attitude of not being happy and satisfied with our own medical field is being observed not only in urology but in all the medical specialties in India.

A study done at UK and Ireland revealed self-reported level of chronic stress and burnout experienced by urologists was $52 \%$. This is higher than urologists in the USA which has the incidence of $40 \%$ and also higher than other reported specialties such as general surgery (50\%), orthopaedics (45\%), and plastic surgery (45\%).3,4,5 Our study results were comparable to stress levels among USA urologists.

In a study done by O'Kelly et al., the highest stress and burnout scores were seen in urologists aged more than 45 years, in private practice, a leadership role in the workplace including hospital management. ${ }^{2}$ The factors that correlated with burnout were identified as administrative work load, volume of work, lack of institutional resources or management support, lack of pension, patient expectations, on-call responsibilities and salary. ${ }^{2}$ Unlike our study results, factors which had the least impact include operating room decision making, research, and medico-legal pressures, probably due to change in working environments, various responsibilities assigned by the institutions, and government schemes and laws in UK and India.

In a multi-centric review revealed that doctors are more at risk of stress and burnout as compared to the general population and among doctors; surgeons had high prevalence of burnout, psychiatric morbidity, and depression, with suicidal ideation rates above those of physicians ${ }^{1}$. They found that workload was the most significant contributor to burnout $^{1}$. For some of the urologists, high workload is the cause of stress. Urologists are getting busier day by day as the life expectancy has increased leading to high old age population with high risk comorbid conditions and urological complaints. India lacks strict guidelines on uniform working hours for doctors as well as remuneration for doctors. Professional factors, such as poor professional relationships, malpractice claims, and work-home conflicts appear to contribute significantly to these phenomena ${ }^{1}$. Even though, the presence of familial and social supports, were supposed to alleviate stress; the impact of professional factors is high enough to cause burnout. 1

Majority of urologists are affected various state and central government health laws and schemes which are governing doctors like consumer protection laws, Ayushman scheme, NMC bill etc. Sometimes doctors become the soft targets in the game of politics. This is an important aspect upon which authorities like Indian urological society, Indian medical association and other medical organizations should look into and to take further actions as it is harming the health of the doctors.

On evaluating how the laws are affecting the life of an urologist, Majority expressed that they feel helpless and as though their hands are tied; feeling of frustration. These emotions can affect both the quality of medical care and the physician's own sense of well-being, since unexamined emotions may also lead to physician distress, disengagement, burnout, and poor judgment. 6 Working with such kinds of helpless feelings is neither good for the patients or for the surgeons and the hospital. Job satisfaction can act as a protective factor against stress and burnout. ${ }^{4}$

In our study stress levels were more among free lancing urologists as compared to urologists attached to teaching institute or an organization. But a Germany study revealed, urologists who practiced in academic institutions had higher burnout compared to urologists practicing in a private/community setting which was attributed to multiple administrative roles. But there is evidence that academic practice acts as a protective factor against stress and burn out ${ }^{1}$. Other protective factors included marriage or spousal support, career satisfaction and autonomy ${ }^{1}$. Young urologists aged less than 45 years are more stressed than old urologists. Our results were similar to study done among Germany urologists ${ }^{7}$ and urologists in UK and Ireland. ${ }^{2}$ Sharma et al. reported that Depersonalization was more common in 
younger colorectal and vascular surgeons, and that those surgeons planning to take early retirement were more likely to have psychiatric morbidity associated with burnout ${ }^{8}$. The possible explanation for higher levels of stress among free lancing urologists could be due to lack of stability at one place or could be due to arranging operating theatres, anaesthesiologists, and lack of well-trained staff. ${ }^{9}$

When stress persists for a long time it leads to a syndrome of Burnout. The term "burnout" was first coined by Dr. Herbert J. Freudenberger in his 1980 book Burnout: the High Cost of Achievement, where he defined it as, "The extinction of motivation or incentive, especially where one's devotion to a cause or relationship fails to produce the desired results ${ }^{10}$. Though there is huge medical research and increased awareness about burnout, still the incidence of burnout amongst doctors continues to climb. ${ }^{11}$ One of the largest studies, involving more than 35,000 physicians in the United States, revealed $10 \%$ rise in burnout and $8 \%$ decline in the satisfaction of work-life balance (WLB) in 2014 as compared to 2011 studies. ${ }^{12}$ Urologists had high rate of burnout (67\%) and lower satisfaction rates. Other specialties with high burnout and low satisfaction with WLB were family medicine, neurology, orthopaedic surgery and general internal medicine. Specialties ranking lowest on the burnout inventory included general surgery, paediatric subspecialties, psychiatry and preventative and occupational medicine.

When more than one third of surgeons experience burnout and low job satisfaction, there is a risk of losing a major component of our work force to early retirement and potential substance abuse which could adversely affect the quality of care provided to patients across the medical spectrum ${ }^{11}$. Today young urologists are more stressed and burnout permeates our medical culture as early as residency training and continues to be a major factor in job dissatisfaction, interpersonal conflicts and substance abuse even for urologists who are well into their senior years of practice. ${ }^{11,13}$

Several risk factors have been identified by the American Medical Association to be associated with higher rates of physician burnout ${ }^{14}$ which include: demanding clinical workload, increased number of nights on call, a partner who also is a physician, young children to raise, a recently encountered medical error, mid-level career, conflicts between work-life balance, and less than $20 \%$ of their time spent on the most meaningful aspects of work. ${ }^{14}$ These principles have been reported across many surgical subspecialties; including obstetrics/gynaecology, otolaryngology, and orthopaedic surgery, where the investigators found that increasing hours worked per week were a statistically significant predictor of burnout, decreased career satisfaction, and poorer overall quality of life. ${ }^{15}$ In line with these reports, dissatisfied physicians were up to 3 times more likely to leave medicine than satisfied physicians, with surgeons being the most likely to retire early. ${ }^{16}$

Stress $=$ Pressures/Resilience. Pressures are as a result of environmental (Workplace related stressors) or Interpersonal (Interaction with others wherein one perceive themselves as powerless to change or control the situation) or personal. Resilience is the inner strength, which when adequate person develops problem solving strategies alleviating the stress. When resilience is inadequate person develops Emotional focused strategies enhancing the effects of stress. Yoga and meditation are one of the tools to develop Inner strength. Yoga and Meditation improve psychological well-being, self-confidence, relive stress, facilitate positive experience, reduces pain perception, headaches and improve sleep. ${ }^{17,18}$

\section{Measures that can be taken by Urology Faculty, USI and other National Medical Bodies like IMA}

- Strengthen USI at local, state and National levels- encourage membership.

- Initiate large scale multicentre studies and rephrase the rules and regulations regarding working hours, various state and central government health schemes, remuneration given to various physicians and surgeons ${ }^{9}$. Voice of national associations should become public voice and fight for doctors rights with a strong representation of doctors at central level.

- Accident and incident conferences should be organized in positive environment where in urologists present the critical situations they encountered, provide opportunity to share practices and discharge overload and emotional stress; could also play a role in the social support.

- Develop web-links (Blogs, videos, etc.) and address the topics like physician wellness, maintaining work-life balance, and tips on handling the first years of practice, provide contact numbers for confidential counselling, suggested readings etc. Online program was launched by the American Medical Association in June 2015 called STEPS Forward, which addresses physician burnout via online educational modules covering key areas such as: practice efficiency and patient care, patient health, physician health, technology and innovation. Same programs can be developed in India as well

- Involvement of local bodies: Society is becoming more litigious- consider local USI/ IMA or similar agencies to provide legal advice, indemnity insurance etc. Local bodies should also ensure adequate staffing at work place like small nursing homes, develop reasonable financial expectations/goals, reduce prolonged stress, restore a sense of control, reduce call obligations, restore lifestyle balance, improve efficiency, reduce isolation and seek professional help. ${ }^{19}$

- To cope with modern work practice, it is essential that additional management and administration skills be included in training and in continued medical education ${ }^{2}$. Increasing intellectual stimulation, allowing better quality of care, improving interaction with patients and providing adequate operating room assistance should be seriously considered.

- Consider Yoga, meditation and other mindfulness-based interventions, counselling sessions/workshops/ seminars are excellent strategies for the prevention and treatment of burnout. 20

- Our study had many limitations. We have not measured the actual stress levels, which could be another level of study. It is also uncertain whether the associative factors proposed are in fact causal; a follow-up survey would provide longitudinal evidence. Future studies could probe more deeply into urological surgeons' personal lives in order to determine the extent this may play in stress and burnout. 


\section{CONCLUSIONS}

There is a high prevalence of stress among Indian urologists especially young and freelancing urologists. There is evidence in the literature that persistent stress leads to a syndrome of burnout which in turn affects health, personal and professional life, ultimately leading to lack of patient care. As an organization with a strong national presence, MCI and Urological Society of India should address these matters and initiate multicentre studies and problem solving strategies involving local bodies as well. Ultimately, it is the responsibility of all the urologists to adapt to stress free life styles and attain work-life balance.

\section{REFERENCES}

[1] Oskrochi Y, Maruthappu M, Henriksson M, et al. Beyond the body - a systematic review of the non-physical effects of a surgical career. Surgery 2016;159(2):650-64.

[2] O'Kelly F, Manecksha RP, Quinlan DM, et al. Rates of self-reported 'burnout' and causative factors amongst urologists in Ireland and the UK: a comparative cross-sectional study. BJU Int 2016;117(2):363-72.

[3] Balch CM, Shanafelt TD, Sloan JA, et al. Distress and career satisfaction among 14 surgical specialties, comparing academic and private practice settings. Ann Surg 2011;254(4):558-68.

[4] Shanafelt TD, Balch CM, Bechamps GJ, et al. Burnout and career satisfaction among American surgeons. Ann Surg 2009;250(3):463-71.

[5] Balch CM, Shanafelt T. Combating stress and burnout in surgical practice: a review. Adv Surg 2010;44(1):29-47.

[6] Meier DE, Back AL, Morrison RS. The inner life of physicians and care of the seriously ill. JAMA 2001;286(23):3007-14.

[7] Böhle A, Baumgärtel M, Götz ML, et al. Burn-out of urologists in the county of Schleswig-Holstein, Germany: a comparison of hospital and private practice urologists. J Urol 2001;165(4):1158-61.

[8] Sharma A, Sharp DM, Walker LG, et al. Stress and burnout in colorectal and vascular surgical consultants working in the UK National Health Service. Psychooncology 2008;17(6):570-6.
[9] Kamat CA, Todakar M, Rangalakshmi S, et al. Awareness about scope of anaesthesiology, attitudes towards the speciality and stress levels amongst postgraduate students in anaesthesiology: a cross-sectional study. Indian Journal of Anaesth 2015;59(2):110-17.

[10] Freudenberger HJ, Richelson G. Burn-out: the high cost of achievement. Garden City, NY: Anchor Press 1980.

[11] Franc-Guimond J, McNeil B, Schlossberg SM, et al. Urologist burnout: frequency, causes and potential solutions to an unspoken entity. Can Urol Asso Journal 2018;12(4):137-42.

[12] Shanafelt TD, Hasan O, Dyrbye LN, et al. Changes in burnout and satisfaction with work-life balance in physicians and the General US Working Population between 2011 and 2014. Mayo Clin Proc 2015;90(12):1600-13.

[13] Roumiguie M, Game X, Bernhard JC, et al. Does the urologist in formation have a burnout syndrome? Evaluation by Maslach Burnout Inventory (MBI). Prog Urol 2011;21(9):636-41.

[14] Rees L. 8 things that can put you at risk of burnout. https://wire.ama-assn.org/practice-management/8things-can-put-you-risk-burnout

[15] Pulcrano M, Evans SR, Sosin M. Quality of life and burnout rates across surgical specialties: a systematic review. JAMA Surg 2016;151(10):970-8.

[16] Landon BE, Reschovsky JD, Pham HH, et al. Leaving medicine: the consequences of physician dissatisfaction. Med Care 2006;44(3):234-42.

[17] Kiran U, Ladha S, Makhija N, et al. Role of Rajyoga meditation for modulation of anxiety and serum cortisol in patients undergoing coronary artery bypass surgery: A prospective randomized control study. Annals of Cardiac Anaesthesia 2017;20(2):158-62.

[18] Telles S, Desiraju T. Autonomic changes in Brahmakumaris Raja yoga meditation. Int J Psychophysiol 1993;15(2):147-52.

[19] Harolds JA, Parikh JR, Bluth EI, et al. Burnout of radiologists: frequency, risk factors and remedies: a report of the ACR Commission on Human Resources. J Am Coll Radiol 2016;13(4):411-6.

[20] Daniels AH, DePasse JM, Kamal RN. Orthopaedic surgeon burnout: diagnosis, treatment and prevention. J Am Acad Orthop Surg 2016;24(4):213-9. 